\title{
What is the role for carbon cycle science in the proposed EPA power plant rule?
}

\author{
Kevin Robert Gurney
}

\begin{abstract}
On June 2, 2014, the United States Environmental Protection Agency proposed goals and guidelines aimed at lowering carbon dioxide $\left(\mathrm{CO}_{2}\right)$ emissions from existing power plants in the United States. Should it be successfully implemented, US power plant $\mathrm{CO}_{2}$ emissions would be reduced approximately 30 percent below 2005 levels by the year 2030 . Rather than a single national reduction goal, the proposed rule specifies reduction targets unique to each US state but leaves the means by which states meet those targets, flexible to individual state conditions. Regardless of the policy mixture adopted in each US state, quantification of $\mathrm{CO}_{2}$ emissions at the level of individual power plants will be a critical need. Recent research examining power plant $\mathrm{CO}_{2}$ emissions has noted potentially large uncertainties at the individual facility level, uncertainty that remains poorly understood. At the same time, carbon scientists working on aspects of monitoring, reporting and verification of anthropogenic $\mathrm{CO}_{2}$ emissions have developed a mixture of measurement and modeling capabilities as part of the development of a "carbon monitoring system", that could assist in assessing how well independent emissions quantification is performing currently and identify a path towards improved monitoring. Equally important is an assessment of uncertainty at the various space and time scales the EPA proposed rule implies. Application of these recent scientific capabilities to the needs of the EPA's proposed rule could offer a cogent, near-term example of how scientific research can directly enable better decision-making. This paper provides a review of the proposed rule and what role scientific research could play in the evolution of the rulemaking and its application in the future.
\end{abstract}

Keywords: Climate change; $\mathrm{CO}_{2}$ emissions; Power plants; Environmental Protection Agency; Carbon science; Climate policy

\section{Background}

Under authority provided by the United States Clear Air Act, the United States Environmental Protection Agency (EPA) submitted a proposed regulation on June 2, 2014 titled "Carbon Pollution Emission Guidelines for Existing Stationary Sources: Electric Utility Generating Units" (United States Environmental Protection Agency: Carbon Pollution Emission Guidelines for Existing Stationary Sources: Electric Utility Generating Units \& Signed and noticed by EPA Administrator Gina McCarthy on June 2 2014). The rule proposes state-specific targets for lowering the average emission rate (lbs $\mathrm{CO}_{2} / \mathrm{MWhr}$ ) from a state's electricity generation units (EGUs). The targets are to be achieved by the year 2030 and represent reductions relative to the year 2012 (see Figure 1). The EPA also proposed an "interim" goal that states must meet over the 2020-2029 time period to ensure compliance with the final target in 2030. For example, the state of Arizona must lower its state-average emission rate from a 2012 mean value of $1,518 \mathrm{lbs} \mathrm{CO}_{2} / \mathrm{MWh}$ to a final level of 702 lbs $\mathrm{CO}_{2} / \mathrm{MWhr}$ by the year 2030 with an interim target of $735 \mathrm{lbs} \mathrm{CO}_{2} / \mathrm{MWhr}$ (measured as an average of the 20202029 time period). In percentage terms, the 2030 target is equivalent to a $55 \%$ reduction.

The state targets as prescribed in the proposed rule were arrived at by sequentially lowering state-average fossil fuel $\mathrm{EGU} \mathrm{CO}_{2}$ emission rates through the application of a series of "building blocks" - policies and measures that reflect what the EPA considered best practices in power plant $\mathrm{CO}_{2}$ emissions reduction. The starting point of the state-average fossil fuel $\mathrm{CO}_{2}\left(\mathrm{FFCO}_{2}\right)$ emission rate was a 2012 baseline level. The four building blocks are:

Correspondence: kevin.gurney@asu.edu

School of Life Sciences, Arizona State University, Tempe, AZ 85287, USA 


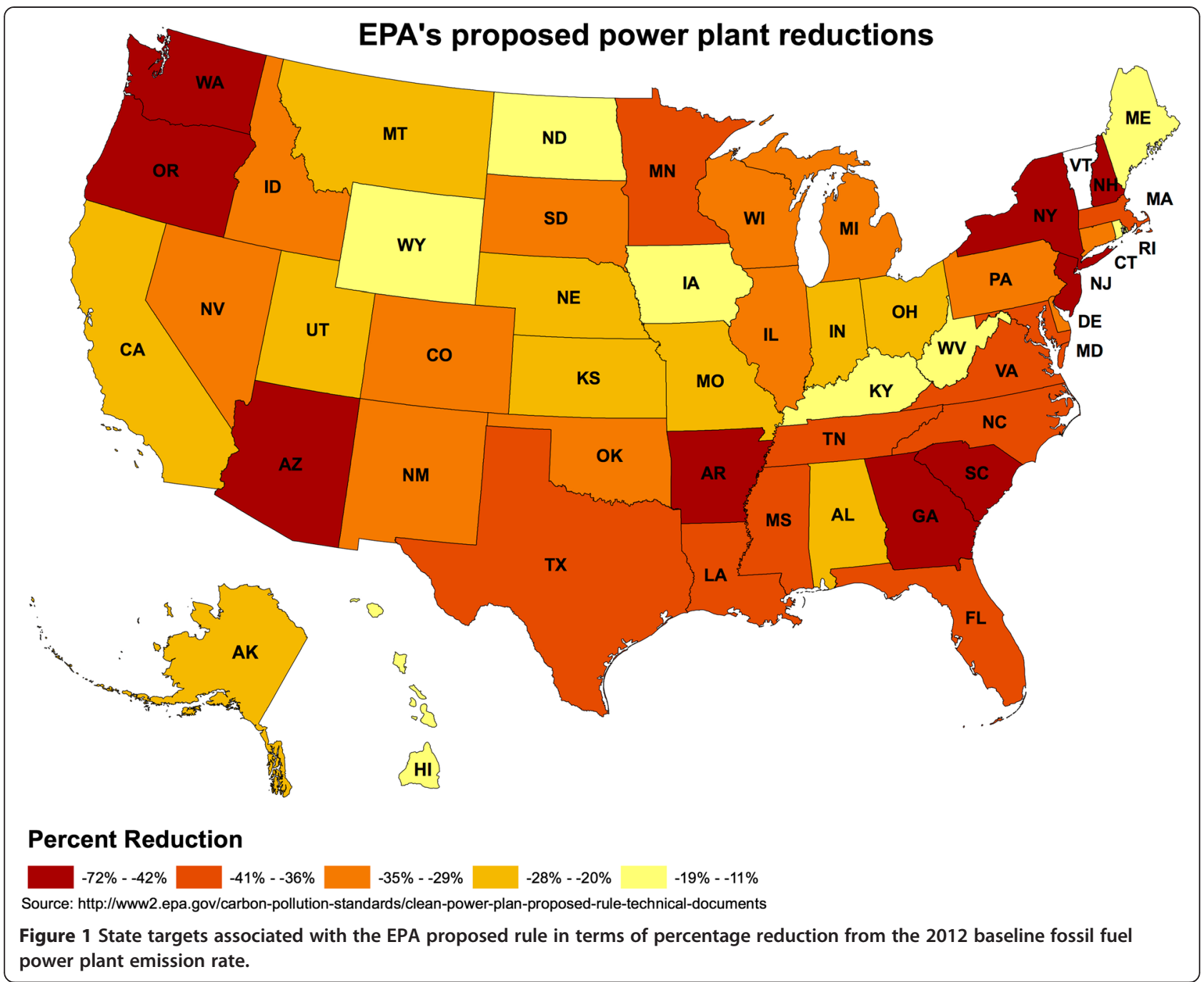

1. Improving the efficiency of individual power plants (getting more electrical output per thermal unit of fuel supplied).

2. Substituting the most carbon-intensive power production (e.g. coal-fired plants) with existing less carbon-intensive production (e.g. natural gas plants).

3. Expanding low- or zero-carbon emitting power production (e.g. wind and solar).

4. Using demand-side energy efficiency as a means to lower electricity generation (numerically incorporated by adding the electricity demand savings to the total electricity production in the emission rate computation).

The degree to which these were applied for each state varied depending upon individual state data and conditions. Though the EPA arrived at the target reductions through the application of these building blocks, the rule does not prescribe these as the means by which states must achieve the reductions. They simply represent guidance on what is considered best practices. States are ultimately tasked with submitting a plan to arrive at the reduction goals using these building blocks or any other mix of policies they consider appropriate to their state's electricity supply and demand conditions. For example, states can implement a cap and trade system in isolation or as part of a multistate collective. States can use carbon capture and storage (CCS), impose a carbon tax, or rely heavily on expansion of renewables. Furthermore, states can opt to use a mass-based target (i.e. total emitted $\mathrm{CO}_{2}$ ) rather than an emission rate target as long as the state emission rate target is properly converted.

The proposed rule is currently in a comment period which closed at the end of the calendar year 2014. The EPA expects to finalize the rule by June of 2015. At that point, states would have one full year to submit their plans to meet the finalized targets. However, states can garner a one year extension, and if they are part of a multistate effort, a two year extension. If a state does not come up with 
an implementation plan, the EPA can impose a plan themselves. Much could change between now and the issuance of a final rule and some research suggests the regulation is open to legal challenge (Potts \& Zoppo DR: EPA's Clean Power Play: Who Needs Congress? The Electricity Journal 2014).

When examining the state targets, the magnitude of percentage reduction does not necessarily reflect the stringency or overall difficulty faced by a given state, as the targets incorporate historical and projected emission reduction activity, among other factors. For example, the state of Washington has the largest percentage reduction target of all the US states $-72 \%$. However, the state has one dominant coal burning facility, the Transalta Centralia plant, relying on hydropower for the majority of its electricity demand. This coal power plant is already scheduled to be phased out dramatically lowering their state average electricity production emission rate prior to the 2030 proposed rule target (Welch C 2999).

\section{Discussion}

\section{The larger context}

It is worth stepping back from the details of rule to examine what it could mean in the broader context of emission trends and broader climate policy goals. Figure 2A shows historical $\mathrm{FFCO}_{2}$ emissions due to US electricity production from the EPA and as projected by the Department of Energy's Energy Information Administration (EIA) (Department of Energy \& Energy Information Administration: Annual Energy 2014; United States Environmental Protection Agency 2014a). Mostly due to a combination of recession and a shift to natural gas in the power production

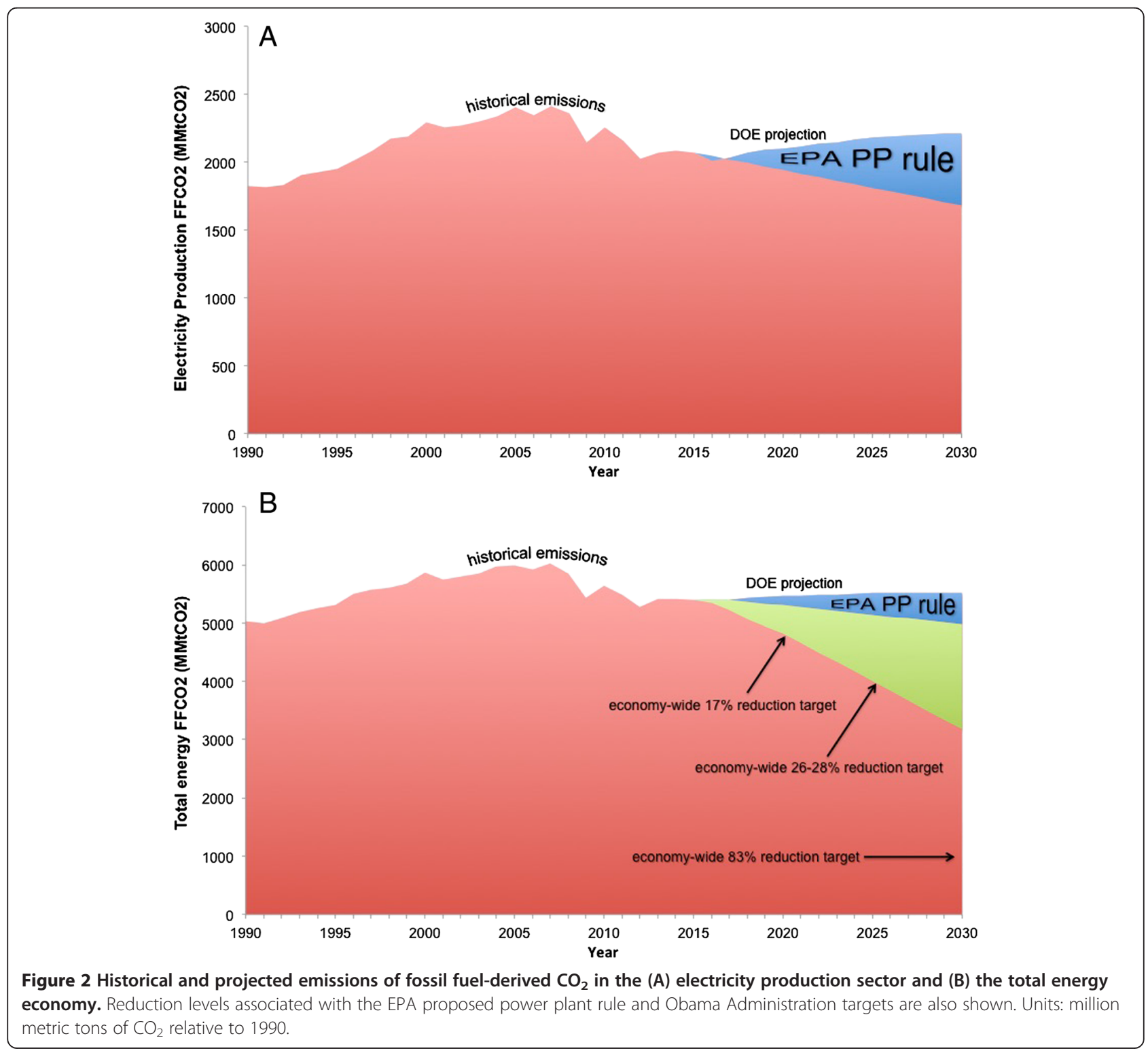


sector, $\mathrm{FFCO}_{2}$ emissions from US electricity production in 2012 were 15.8\% below their 2005 levels (Council of Economic Advisors 2013). Assuming no policy and a business as usual scenario, the EIA projects $\mathrm{FFCO}_{2}$ emissions from the electricity production sector to increase between now and 2030 by roughly $9.5 \%$, still below the 2005 levels. Hence, were the EPA's estimated 30\% reduction target achieved, this would require a $17 \%$ reduction between now $(2012)^{\mathrm{a}}$ and 2030. In short, we are almost halfway to the reduction target already.

Because the $\mathrm{CO}_{2}$ emissions from the electricity production sector represent about one-third of total US greenhouse gas emissions, the reduction expected should the proposed power plant rule play out as the EPA expects, is less dramatic when incorporated into the overall US greenhouse gas emissions (Figure 2B). Using the same EIA reference scenario, the power plant rule would lead to a decline in US energy-related $\mathrm{FFCO}_{2}$ emissions of about 5.6\% between now (2012) and 2030. However, the power plant rule cannot be examined in isolation from the two economy-wide emission reduction pledges made by Obama Administration. The first committed to a $17 \%$ reduction in greenhouse gas emissions below 2005 levels by the year 2020 (and an 83\% reduction by 2050) (United Nations Framework Convention on Climate Change 2010; United States Department of State 2010) while the second committed to lowering greenhouse gas emissions 26-28\% from 2005 levels by the year 2025 (White House, FACT SHEET 2014). The economy-wide reduction of $17 \%$ below 2005 levels by the year 2020 achieves nearly the same absolute carbon reduction amount as the power plant rule, but does so 10 years earlier. ${ }^{\mathrm{b}}$ By the year 2030, the power plant rule would account for roughly $1 / 3$ of the total economy-wide reduction should all the commitments be realized.

\section{The role of carbon science}

In order to exhibit compliance with the targets established in the proposed rule, state's will have to measure or otherwise estimate their state-average $\mathrm{EGU} \mathrm{CO}_{2}$ emission rate. Such measurements or estimation procedures will depend upon the mix of policies and measures adopted to meet their target. For example, demand side energy efficiency improvements will require a means to estimate the amount of electricity demand obviated. Expansion of nuclear or renewable electricity supply will require estimation of the amount of zero-carbon electrical generation. However, because fossil fuel EGUs will remain a component of all state's energy supply and is the part of the US emitting landscape targeted by the proposed rule, it will be essential to measure or otherwise estimate the amount of $\mathrm{CO}_{2}$ emitted at the power plant level. This will be important in planning, implementing and verifying the emission rate goals.
Which raises a very important question: How are state's expected to demonstrate compliance with the state-average emission rate target amount? On this point, the proposed rule is noncommittal other than to suggest that state must include in the reduction plan, means by which their baseline and reduction amounts are quantified.

However, one does not have to look much further than the proposed rule calculations themselves to understand the likely means by which state's will do such quantification. In arriving at the state-average target $\mathrm{CO}_{2}$ emission rates, the EPA relied upon a database of power plant characteristics that combines data from collection efforts at the Department of Energy's Energy Information Administration (EIA) and the Environmental Protection Agency's Clean Air Markets Division (CAMD) (United States Environmental Protection Agency 2014b). The EPA's data collection effort is focused on establishing regulatory compliance of sulfur dioxide $\left(\mathrm{SO}_{2}\right)$ and nitrogen oxides (NOx) emissions and primarily uses stack monitoring (United States Environmental Protection Agency 2005). The continuous emissions monitoring system (CEMs) simultaneously measures the concentration and gas flow rate in the power plant exhaust stack, arriving at a mass flow rate of $\mathrm{CO}_{2}$ emissions. The EIA, by contrast, is focused on maintaining statistics on fuel consumption and electricity production and hence, relies primarily on fuel calculation procedures to estimate emissions. Hence, these two approaches should quantitatively agree within fractions of a percent, given that one is based on the carbon going into a power plant and the other is based on the carbon exiting.

However, recent research suggests that these two datasets exhibit a surprising level of disagreement at the individual power plant level (Ackerman \& Sundquist 2008; Quick 2014; Gurney et al. 2014). Integrated across all US power plants, the discrepancies tend to cancel, suggesting no overall bias. However, given that the proposed rule is focused on assessment of individual EGUs within a state's plan, the disagreement at the individual facility level is a significant problem that may make plan implementation and verification challenging.

This is precisely where research within the carbon science community can contribute to enabling a better outcome. And it is really a near-term, specific case of a larger effort within the carbon science community to build independent, scientifically-based verification capabilities of greenhouse gas emissions at multiple scales. For example, the National Research Council issued a report in 2010 that reviewed current capabilities for estimating and verifying national GHG emissions and recommendations on improving those capabilities (National Research Council 2010). The National Aeronautics and Space Administration (NASA) has begun an effort on building a Carbon Monitoring System (CMS) which will characterize and quantify carbon stocks and 
flows and use that information to support policy and regulatory needs (NASA Carbon Monitoring System 2999). A CMS will integrate and synthesize a wide variety of observational data on carbon stocks and flows (ground-based, aircraft and space-based) within modeling systems. An outgrowth of the CMS aimed at scales closer to what might be needed for supporting the EPA proposed rule are a series of research efforts in the urban domain, where scientific observational and modeling systems are attempting to quantify fluxes at finer space/time scales and attribute fluxes to sectoral activity or even individual emitting entities (Mays et al. 2009; Gurney et al. 2012; Kort et al. 2012; McKain et al. 2012; Cambaliza et al. 2013; Bréon et al. 2014; Turnbull et al. 2015).

Improved quantification of power plant $\mathrm{CO}_{2}$ emissions and independent verification of those emissions can build from the research conducted at these larger scales in addition to revisiting the current quantification techniques as mandated in the regulatory environment. Both the stack monitoring and the fuel statistical approach are possibly suffering from insufficient calibration or poor instrument maintenance. Research analyzing existing data and testing instrumentation could identify what components of the existing monitoring needs improvement and provide better quantification of uncertainty. Both stack monitoring and fuel monitoring would benefit from better ties to standards established by the National Institute of Standards and Technology (NIST) thereby improving traceability, accuracy, and robustness. Such improvements would offer state's a much better starting point for generating their baselines. As part of a state implementation plan, "spot checks" at power plants could be deployed with independent, scientific grade instrumentation brought in to test systems accuracy and calibration.

Atmospheric monitoring also has a role to play and recent demonstration of results in the Southwest United States is promising. Rodica Lindenmaier and colleagues used remotely-sensed observations of $\mathrm{CO}_{2}, \mathrm{CO}$ and $\mathrm{NO}_{2}$ to evaluate emissions at two large power plants (Lindenmaier et al. 2014). Ideally, a combination of methods are probably best and a mixture of atmospheric monitoring and improved in situ stack monitoring and/or fuel measurements may prove the best solution (Gurney 2013).

At the very least, improved uncertainty quantification associated with baseline and target values within a state's implementation plan might allow for some further flexibility. For example, should a state invest the time and effort in improved monitoring in collaboration with independent scientific efforts, a target might be lessened. Given that some states have targeted reductions less than $15 \%$, uncertainty levels estimated at the individual facility-level may be commensurate with the target and hence, make the verity of meeting a goal, subject to challenge (Ackerman \& Sundquist 2008; Quick 2014;
Gurney et al. 2014). Hence, investment in independent monitoring or assessment using advanced scientific techniques may prove prudent in the long-run, perhaps by easing a challenging reduction target or obviating the time and energy required to defend poorer quality estimation.

Implementation of more advanced scientific measurements and modeling within the proposed rulemaking will need incentives. Though the scientific research cited here has made tremendous progress, its application to this specific need would require targeted funding aimed at a few case studies. For example, access to a few power plants (a mix of size, fuel, technology, age) to test the existing monitoring in place at power plants against the more advanced scientific instrumentation would resolve a number of current questions about accuracy and uncertainty. Linking this to remote of "off-site" measurement and modeling would then allow for an independent, benchmarked, monitoring effort that would interfere with the privacy or proprietary concerns of power producers. This targeted, application-based research could be accomplished in the near-term (3-5 years) and would come at a relatively low cost, as it would leverage the very large investment already made by federal scientific agencies on research into better monitoring and modeling capabilities.

\section{Conclusions}

The proposed rule issued by the United States Environmental Protection Agency is a large step for climate policymaking in the United States. The rule focuses on US power plants and in particular will likely result in a transition away from carbon intensive fossil fuel such as coal and towards natural gas and renewables and encourage energy efficiency. Though the plan leaves implementation up to each individual state, all state's will face the challenge of measuring and monitoring their power plants. Given recent research in the carbon science community, the reliability with which state's will be able to quantify their baseline emission rate and demonstrate compliance in the target years, is a legitimate question. However, there is ongoing work in the carbon science community that may offer independent, scientifically-rigorous means to assess and ultimately better-quantify power plant $\mathrm{CO}_{2}$ emissions and emission rates (Mays et al. 2009; Gurney et al. 2012; Kort et al. 2012; McKain et al. 2012; Cambaliza et al. 2013; Bréon et al. 2014; Lindenmaier et al. 2014; Turnbull et al. 2015). Research could be aimed at better understanding the current monitoring systems to isolate accuracy/ precision problems and improve better uncertainty quantification. Independent methods could be deployed to evaluate in-facility systems either as in-situ testing or using atmospheric monitoring. The latter has made important advances in recent years both from the ground and space. Supporting and enabling the accuracy and verification of emission reductions at power plants is a perfect example 
of the application of research to decision-support. It leverages ongoing research primarily supported through publicly-funded investment in basic research to understand the carbon cycle.

\section{Endnotes}

${ }^{a}$ This is the most recent year for which US emissions data is available.

${ }^{\mathrm{b}}$ Though the Obama administration commitments are reductions in all greenhouse gases, the analysis here scales them to the energy-related $\mathrm{FFCO}_{2}$ amounts, slightly over $80 \%$ of total greenhouse gas emissions.

\section{Abbreviations \\ $\mathrm{CO}_{2}$ : Carbon Dioxide; EGUs: Electrical Generation Units; MWhr: Megawatt hour; CCS: Carbon Capture and Storage; CAMD: Clean Air Markets Division; $\mathrm{SO}_{2}$ : Sulfur dioxide; NOx: Nitrogen oxides; NIST: National Institute for Standards and Technology; CMS: Carbon Monitoring System; \\ CEMs: Continuous monitoring system; $\mathrm{FFCO}_{2}$ : Fossil fuel carbon dioxide; EIA: Energy Information Administration; NASA: National Aeronautics and Space Administration; EPA: Environmental Protection Agency.}

\section{Competing interests}

The authors declare that they have no competing interests.

\section{Authors' contributions}

KRG performed all aspect of research and writing associated with this manuscript.

\section{Authors' information}

KRG is an associate professor in the School of Life Sciences and a Senior Sustainability scientist in the Julie Ann Wrigley Global Institute of Sustainability at Arizona State University.

\section{Acknowledgements}

Thanks to Maya Hutchins for assistance with graphics.

Received: 27 October 2014 Accepted: 6 January 2015

Published online: 29 January 2015

\section{References}

Ackerman KV, Sundquist ET (2008) Comparison of two U.S. power-plant carbon dioxide emissions data sets. Environ Sci Technol 42(15):5688-5693

Bréon FM, Broquet G, Puygrenier V, Chevallier F, Xueref-Rémy I, Ramonet M et al (2014) An attempt at estimating Paris area $\mathrm{CO}_{2}$ emissions from atmospheric concentration measurements. Atmos Chem Phys Disc 14(7):9647-9703. doi:10.5194/acpd-14-9647-2014

Cambaliza MO, Shepson PB, Caulton D, Stirm B, Samarov D, Possolo A et al. (2013) Assessment of the uncertainties of an aircraft-based mass balance approach for quantifying urban greenhouse gas emissions. Atmos Chem Phys Disc 13:29895-29945. doi:10.5194/acpd-13-29895-2013

Council of Economic Advisors (2013) The Annual Report of the Council of Economic Advisors. United States Government Printing Office, Washington

Department of Energy, Energy Information Administration: Annual Energy Outlook 2014 with Projections to 2040, Office of Integrated and International Energy Analysis U.S. US Federal agency, Department of Energy Washington, DC 20585, DOE/EIA-0383, April, 2014.

Gurney KR (2013) Beyond hammers and nails: mitigating and verifying greenhouse gas emissions. EOS Trans Am Geophys Union 94(22):199-200

Gurney KR, Razlivanov I, Song Y, Zhou Y, Benes B, Abdul-Massih M (2012) Quantification of fossil fuel $\mathrm{CO}_{2}$ at the building/street scale for a large US city. Environ Sci Technol 46:12194-12202

Gurney KR, Huang J, Coltin K (2014) J Air Waste Manage Assoc 64(1):73-79, J Air \& Waste Manage Assoc 2014, in press

Kort EA, Frankenberg C, Miller CE, Oda T: Space-based observations of megacity carbon dioxide. Geophys Res Lett 2012, 39, doi:10.1029/2012gl052738.

Lindenmaier R, Dubey MK, Henderson BG, Butterfield ZT, Herman JR, Rahn T, Lee S-H: Multiscale observations of $\mathrm{CO}_{2},{ }^{13} \mathrm{CO}_{2}$, and pollutants at Four Corners for emission verification and attribution. Proc Nat Acad Sci 2014, 111(23), doi: 10.1073/ pnas.1321883111.

Mays KL, Shepson PB, Stirm BH, Karion A, Sweeney C, Gurney KR: (2009) Aircraftbased measurements of the carbon footprint of Indianapolis. Environ Sci Technol 43(20):7816-7823

McKain K, Wofsy SC, Nehrkorn T, Eluszkiewicz J, Ehleringer JR, Stephens BB: (2012) Assessment of ground-based atmospheric observations for verification of greenhouse gas emissions from an urban region. Proc Natl Acad Sci U S A 109(22):8423-8428. doi:10.1073/pnas.1116645109

NASA Carbon Monitoring System [http://carbon.nasa.gov/]

National Research Council (2010) Committee on Methods for Estimating Greenhouse Gas Emissions Verifying Greenhouse Gas Emissions: Methods to Support International Climate Agreements; 9780309152112. The National Academies Press, Washington DC

Potts BH, Zoppo DR: EPA's Clean Power Play: Who Needs Congress? The Electricity Journal 2014, doi:10.1016/j.tej.2014.06.004.

Quick J (2014) Carbon dioxide emission tallies for 210 U.S. Coal-fired power plants: a comparison of two accounting methods. J Air Waste Manage Assoc 64(1):73-79

Turnbull J, Sweeney C, Karion A, Newberger T, Tans P, Lehman S et al. (2015) Towards quantification of fossil fuel $\mathrm{CO}_{2}$ and trace gas emissions from an urban area: Results from the INFLUX experiment, Journal of Geophysical Research, Atmos, 120. DOI: 10.1002/2014JD022555.

United Nations Framework Convention on Climate Change (2010) Report of the Conference of the Parties on its fifteenth session, held in Copenhagen from 7 to 19 December 2009, FCCC/CP/2009/11/Add.1

United States Department of State (2010) Office of Special Envoy for Climate Change, letter to Mr. de Boer from Todd Stern, US Special Envoy for Climate Change

United States Environmental Protection Agency (2005) Plain English Guide to the Part 75 Rule, U.S. Environmental Protection Agency, Clean Air Markets Division

United States Environmental Protection Agency (2014a) Inventory of U.S. Greenhouse Gas Emissions and Sinks: 1990-2012. U.S. Environmental Protection Agency 1200, Pennsylvania Ave., N.W. Washington, DC 20460 U.S.A

United States Environmental Protection Agency (2014b) The Emissions \& Generation Resource Integrated Database, Technical Support Document for the $9^{\text {th }}$ Edition of eGRID with Year 2010 Data, Prepared for: Clear Air Markets Division, Office of Atmospheric Programs. U.S. Environmental Protection Agency, Washington DC, p 20460

United States Environmental Protection Agency: Carbon Pollution Emission Guidelines for Existing Stationary Sources: Electric Utility Generating Units, Signed and noticed by EPA Administrator Gina McCarthy on June 2, 2014 Available at: http://www2.epa.gov/carbon-pollution-standards/clean-power-planproposed-rule

Welch C, Lindblom M: Agreement reached to stop burning coal at Centralia power plant. [http://seattletimes.com/htm//localnews/2014412221_coalplant06m.html]

White House, FACT SHEET (2014) U.S.-China Joint Announcement on Climate Change and Clean Energy Cooperation., http://www.whitehouse.gov/thepress-office/2014/11/11/fact-sheet-us-china-joint-announcement-climatechange-and-clean-energy-c

\section{Submit your manuscript to a SpringerOpen ${ }^{\odot}$ journal and benefit from:}

- Convenient online submission

- Rigorous peer review

- Immediate publication on acceptance

- Open access: articles freely available online

- High visibility within the field

- Retaining the copyright to your article

Submit your next manuscript at $\boldsymbol{\wedge}$ springeropen.com 